\title{
LA BIOÉTICA EN LAS CONSTITUCIONES DEL MUNDO*
}

\author{
Enrique Varsi Rospigliosi**
}

\begin{abstract}
Resumen: El autor realiza un análisis del Derecho Constitucional comparado, identificando 37 leyes fundamentales que consideran dentro de sus normas principios de orden bioético, tales como el respeto de la dignidad humana en todo lo relacionado con la investigación científica, la protección de la identidad genética, el derecho a investigar la paternidad, el reconocimiento de los derechos de las generaciones futuras, etc.

En el Congreso peruano existe una propuesta tendiente a incorporar en la futura Constitución normas de contenido bioético. En ella se plantean varios de los principios señalados precedentemente y otros que, de ser acogidos en la Carta Fundamental, transformarán a Perú en pionero en la regulación constitucional de las nuevas materias relacionadas con las ciencias de la vida.
\end{abstract}

Palabras clave: Bioética, constitución, derechos humanos, derecho genético, consentimiento informado

\section{BIOETHICS IN THE WORLD'S CONSTITUTIONS}

\begin{abstract}
The author analyses a compared Constitutional Law, identifying 37 fundamental laws that include bioethic principles in their norms, such as the respect for human dignity in everything related to scientific investigation, genetic identity's protection, the right to investigate paternity, recognition of future generation's rights, etc.

A proposition to incorporate bioethic norms in the future Constitution was made by the Peruvian Congress. Several of the principles just mentioned, and others stated there, if approved in the Fundamental Chart, will turn Peru into the pioneer in constitutional regulation of the new topics related to life's sciences.
\end{abstract}

Key Words: Bioethics, constitution, human rights, genetic right, informed consent

\section{A BIOÉTICA E AS CONSTITUIÇÕES DO MUNDO}

Resumo: O autor realiza análise do Direito Constitucional comparado, identificando 37 leis fundamentais que consideram em suas normas princípios bioéticos, tais como respeito à dignidade humana em pesquisa científica, proteção à identidade genética, direito a investigar a paternidade, reconhecimento dos direitos das gerações futuras, etc...

Em tramitação no Congresso Peruano há uma proposta que pretende incorporar na futura Constituição, normas de conteúdo bioético. Nela estão acolhidos vários dos princípios já mencionados além de outros que deverão ser incorporadas na Carta Fundamental, o que transformará o Peru em país pioneiro na regulamentação constitucional de matérias relacionadas com as ciências da vida.

Palavras chave: Bioética, constituição, direitos humanos, direito genético, consentimento informado.

\footnotetext{
* Esta es una investigación más extensa y mucho más informada, publicada en diversos periódicos peruanos.

** Doctor en Derecho. Miembro del Comité Intergubernamental de Bioética de la UNESCO. Miembro del Consejo Nacional de Bioética del Perú. Profesor de Derecho Genético en la Universidad Nacional Mayor de San Marcos y en la Universidad de Lima Correspondencia: enrique@chehadevarsi.pe
} 


\section{Introducción}

Hoy más que nunca el ser humano ve amenazada su existencia por el veloz desarrollo de las técnicas biomédicas. Esta situación merece una reflexión profunda y una respuesta idónea del Derecho, al que le urge juridificar a nivel constitucional ciertos principios bioéticos, reconociendo el respeto a las personas, la beneficencia y la justicia, que representan los principios conservadores de la bioética. Para ello, deberá repensar las normas plasmadas en la Constitución, tomando en cuenta los documentos internacionales que se han venido aprobando, entre ellos, la Declaración Universal de los Derechos Humanos ${ }^{1}$, la Declaración de $\mathrm{Helsinki}^{2}$, la Declaración de Bilbao ${ }^{3}$, la Declaración Universal sobre el Genoma Humano y los Derechos Humanos ${ }^{4}$, el Convenio de los Derechos Humanos y la
Biomedicina $^{5}$, la Declaración Bioética de Gijón $^{6}$, la Carta de Derechos en Genética ${ }^{7}$, la Declaración Ibero-Latinoamericana sobre Derecho, Bioética y Genoma Humano ${ }^{8}$, así como el Derecho comparado en general y el nacional en particular, a efectos de dejar sentada su posición en su norma fundamental.

Los derechos fundamentales de la persona representan la columna vertebral de toda Constitución, pues permiten la vida de relación. En este sentido, si a la fecha la biotecnología es una de las principales fuentes de vulneración de los derechos y de la vida propiamente dicha, es lógico que la Carta Magna se encargue de la regulación jurídica de la bioética, independientemente de que otras normas especiales traten la materia, como es el caso del Código Civil, la ley de salud u otras más concretas.

\section{Bioética y Derecho Constitucional}

Llegar a establecer la importancia de que un texto constitucional regle los principios de orden bioético presenta variadas vertientes. Por

5 Aprobado por el Comité de Ministros del Consejo de Europa el 19/11/1996. Se le conoce también como: Convenio de Asturias, Convenio de Oviedo, Convenio de Bioética para la medicina o Convenio de Bioética. Este documento sí tiene fuerza vinculante y debe ser cumplido por los países firmantes. A pesar de que el Perú no es parte del Consejo de Europa, el artículo 34 (Estados no miembros) determina que "1. Una vez entrado en vigor el presente Convenio, el Comité de Ministros del Consejo de Europa podrá invitar a adherir al presente Convenio, previa consulta a las Partes, a cualquier Estado no miembro del Consejo de Europa mediante una decisión adoptada por la mayoría prevista en el artículo 20, párrafo d), del Estatuto del Consejo de Europa, y por unanimidad de los votos de los representantes de los Estados Contratantes que tengan derecho a estar representados en el Consejo de Ministros".

6 I Congreso Mundial de Bioética, Gijón, España, 20-24 de junio de 2000.

7 Emitido por el "Council for Responsible Genetics" (Consejo para una Genética Responsable), publicado en: Bulletin of Medical Ethics May 2000; 158: 7.

8 Declaración de Manzanillo de 1996, revisada en Buenos Aires en 1998 y en Santiago de Chile en 2001. 
un lado, podemos apreciar que los especialistas en materia bioética son propensos a aplaudir esta inclusión; otros prefieren mantener en la especialidad normativa los aspectos de la biotecnología; por su parte, algunos autores no muestran una posición clara sobre el tema, y esto es lógico, por la poca difusión o importancia que se le da actualmente a la bioética.

Podemos plantear a este respecto dos criterios, uno a favor y el otro en contra.

\section{a) Afavor}

Genival Veloso De França(1) nos refiere que: "é muito auspicioso que na futura Constituição do Perú sejam inseriudos dispositivos voltados aos princípios bioéticos onde fiquem patentes a protecção diante de todo experimento genético ou tecnologico, o dereito à identidade genética, a proteção do patrimônio germinal e genético como respeito à dignidade da pessoa humana e da familia, a confidencialidade de seus dados genéticos e que o patrimônio genético só venha a ser revelado com o consentimento livre e esclarecido do investigado. Enfim, que todo progresso que se venha obter através do estudo do genoma humano seja sempre em favor de cada homem e de cada mulher, e no conjunto dos teresses da coletividade".

Adelio Misseroni $i^{9}$ menciona que "resulta absolutamente innecesario que me refiera a la importancia de elevar a rango constitucional ciertos principios bioéticos básicos... La fuerza que el debate sobre estos temas está adquiriendo es, a todas luces, evidente. Con este proyecto, el Perú no hace más que confirmar su rica tradición jurídica". Asimismo, José Geraldo de Freitas Drumond ${ }^{10}$ dice que "es un

\footnotetext{
9 Abogado. Profesor de Derecho Civil en la Universidad de Magallanes (Chile). Consultor del Programa Regional de Bioética OPS/OMS.

${ }^{10}$ Presidente de la Sociedad Brasileña de Derecho Médico. Rector de la Universidad Estatal de Montes Claros, Minas Gerais, Brasil.
}

avance temático de las Cartas Mayores que buscan garantizar los derechos a la integridad del patrimonio genético de los pueblos".

Roberto Andorno" indica: "Considero fundamental que ciertos principios orientadores de las denominadas cuestiones de «bioética» (que, más allá de la ambigüedad de la palabra, no pertenecen sólo al ámbito ético, sino también al jurídico) adquieran rango constitucional. No hay que olvidar que en dichas cuestiones entran en juego valores básicos de la existencia humana, tales como la vida, la identidad de las personas y la libertad de toda predeterminación por parte de terceros. Los poderes inéditos que la tecnología nos confiere sobre nuestros semejantes, y sobre el futuro mismo de la especie, exigen ineludiblemente una respuesta jurídica del más alto nivel, es decir, de rango constitucional, para proteger la dignidad humana. Cabe señalar que, hasta el momento, Suiza es el único país en el mundo que ha introducido en su Constitución algunas reglas orientadoras del desarrollo biomédico. Si Perú logra realizar algo semejante, ello constituirá sin duda un gran orgullo para toda Latinoamérica”.

Eddy F. Ruíz La Rosa ${ }^{12}$ nos dice que como derecho de la tercera generación son pocas las constituciones que lo tienen incorporado y debe trabajarse profundamente en su elaboración, pues no hay referencia en cuanto a su estructura y formulación.

Alfonso Atela13 nos propone que "para forjar una Constitución moderna y duradera, dig-

\footnotetext{
${ }^{11}$ Profesor de Derecho Civil en la Universidad de Buenos Aires (1995-1998). Miembro del Comité Internacional de Bioética de la UNESCO. Investigador del Departamento de Ética Médica de la Universidad de Göttingen (Alemania).

12 Abogado. Profesor de la Facultad de Derecho de la Universidad de Oriente (Santiago de Cuba, Cuba).

13 Abogado del Colegio de Médicos de Vizcaya. Vocal de la Asociación Española de Derecho Sanitario. Vocal de la Sociedad Iberoamericana de Derecho Médico (SIDEME). Profesor del Master de Práctica Jurídica de la Universidad de Deusto y del Colegio de Abogados del Señorío de Vizcaya.
} 
na de un Estado Democrático del siglo XXI, en primer lugar debéis pensar qué modelo de sociedad queréis y, a partir de ahí, dotar a vuestra Constitución de tres requisitos fundamentales en materia de bioética:

a. Otorgar rango constitucional a los principios bioéticos más importante. Todo aquello que sea un principio básico, fundamental, conforme al cual queremos desarrollar el modelo de sociedad en el que previamente hemos pensado, debe ser reflejado en la Constitución para que sirva siempre de referente, para que sea el norte hacia el que se dirija la sociedad y sus tres poderes (ejecutivo, legislativo y judicial). De allí que los principios bioéticos deberían tener rango constitucional.

b. Disponer sobre ellos una regulación especial mínima. La Constitución ha de modificarse lo menos posible, ha de ser el instrumento para el desarrollo de una sociedad a largo plazo, una apuesta de futuro. No tiene que ser inmutable (allá donde se aprecie un fallo habrá que modificarlo), pero es preciso que sea la norma con mayor seguridad jurídica del Estado. Por ello debe contener una regulación, por decirlo de forma gráfica, de trazo grueso, meras pinceladas perfilando lo más importante, lo que creemos que (seguramente) no va a cambiar sino a muy largo plazo. El trazo fino quedaría para la normativa de desarrollo constitucional, pues una regulación constitucional demasiado extensa es más probable que exija modificaciones a medio plazo, y es más senci$1 l o$ (y, sobre todo, menos inseguro jurídicamente) modificar la Ley que la Constitución. Este tema debe tenerse muy en claro al momento de constitucionalizar los principios de la bioética.

c. Establecer el principio de reserva de Ley Orgánica (o, al menos, de Ley Formal) para su normativa de desarrollo. Una cosa es que la normativa bioética no haya de regularse al detalle en la Constitución y otra, muy distinta, que pueda hacerse mediante norma de otro rango. También aquí en el punto medio está la virtud y, a medio camino de las dos opciones está que, una vez otorgado rango constitucional a lo básico y primordial, el desarrollo de aquello que tanta importancia tiene se reserve a norma cuya modificación ni sea tan dificultosa (y desaconsejable) como la de la Constitución, ni se convierta en un mero trozo de barro maleable por cada gobernante mediante el oportuno (u oportunista) decreto, etc. Hay que tener en cuenta, además, que tampoco la Ley que desarrolle los principios constitucionales básicos ha de ser la última norma sobre la materia, sino que puede, a su vez, disponer ulterior desarrollo reglamentario por el Gobierno en las cuestiones administrativas y, en general, en las de menor importancia".

\section{b) En contra}

Debemos aclarar que si bien no es un criterio totalmente antagónico a la inclusión de normas bioéticas en la Constitución, Gonzalo Figueroa Yáñez ${ }^{14}$ nos detalla algunas reservas. Al respecto nos indicó, de manera clara y precisa, que "La Ley Suprema juega funciones diferentes, según el país de que se trate. En aquellos lugares en que la modificación de las leyes es un trámite fácil, sujeto a las mayorías políticas que contingentemente puedan existir en los Parlamentos o en los casos de existir legislativos obsecuentes al gobierno, la incorporación de ciertos principios en el ordenamiento constitucional conlleva un significado de inmutabilidad, de permanencia o de fijación de aquellos principios, que puede ser de mucha utilidad. En cambio, en aquellos otros países en que es el estatuto legislativo el que tiene ciertas características de inmutabilidad o permanencia, no tiene sentido 'constitucionalizar' los principios que ya tuvieron acogida legislativa. Lo mismo puede decirse respecto de la mutabi-

\footnotetext{
${ }_{14}$ Profesor Titular de Derecho Civil de la Universidad de Chile y de la Universidad Diego Portales. Director del Instituto de Investigaciones Fernando Fueyo Laneri. Ex embajador de Chile ante la Unesco.
} 
lidad o inmutabilidad de una cierta jurisprudencia uniforme: si las sentencias de los tribunales se han inclinado invariablemente en un cierto sentido, puede incluso ser innecesario trasladar ese criterio al ámbito legislativo. Las consideraciones anteriores nos llevan al punto esencial que debe responderse al momento de proponer la 'constitucionalización' de alguna norma: ¿Para qué se quiere llevar un cierto principio al nivel constitucional? Yo he sostenido en mi libro(2) que el tratamiento legislativo del Derecho de la Persona fue sacado del Derecho Privado por consideraciones políticas propias de la situación que desembocó en la Revolución Francesa. Frente a los atentados de las monarquías absolutas contra los derechos básicos de los ciudadanos, a las "lettres de cachet", a la inseguridad personal y al poder omnímodo de los reyes, parecía recomendable encontrar un refugio para las personas en el propio texto constitucional. Como esas consideraciones han cambiado, nada impide que el tratamiento jurídico extensivo respecto de las personas vuelva a su lugar de origen y se reincorpore como materia fundamental del Derecho Civil. Todo lo anterior lo lleva a uno a preguntarse: ¿Para qué se desea incorporar en la Constitución Política del Perú algunos principios de bioética? ¿Es que no basta en ese país el nivel legislativo o el nivel jurisprudencial? La pregunta tiene especial interés frente a una materia tan cambiante, tan novedosa, tan innovativa, como son las investigaciones y descubrimientos biogenéticos, en que cada día nos encontramos con sorpresas nunca antes imaginadas, y en que pudiera parecer inconveniente 'fijar' normas, al elevarlas al nivel constitucional. Las razones anteriores me llevan -en la perspectiva que tengo desde Chile- a tomar una actitud suspensiva frente a la proposición que Ud. ha hecho al Congreso del Perú, para incorporar algunos principios bioéticos en la Constitución Política de esa nación. Declaro, sin embargo, que no tengo competencia para opinar sobre esta materia desde la única perspectiva válida y posible, como es la que se tiene desde el propio Perú".

Estos dos criterios no hacen más que determinar la importancia del tema de la bioética. Queda por definirse la posibilidad y necesidad que el texto constitucional ampare estos principios.

\section{Los Principios Bioéticos en el Derecho Constitucional Comparado}

Existe un buen número de países $(37)^{15}$ que considera dentro de sus normas constitucionales principios de orden Bioético y del Derecho genético, tomando en cuenta que la biotecnología debe ser regulada en un primer orden por la Constitución, "ley de leyes", y ser reglamentada en normas especiales y típicas. Actualmente, muchas Constituciones se abocan a normar el avance de la biotecnología, la procreática $y$, recientemente, la genómica. En ellas se cautela en forma efectiva e inmediata con rango supremo los derechos humanos, al ser humano, al medio ambiente y a todo lo que implica vida.

Aquellos países que consideran dentro de sus preceptos constitucionales normas de bioética son Argentina (Buenos Aires, Santa Cruz, Santa Fe), Armenia, Bielorrusia, Bolivia, Brasil, Colombia, Costa Rica, Croacia, Cuba, Chechenia, Ecuador, Egipto, El Salvador, Eslovenia, España, Estados Unidos (Washington), Estonia, Guatemala, Honduras, Italia, Japón, Lituania, Nicaragua, Noruega, Panamá, Paraguay, Polonia, Portugal, Québec (Proyecto de Constitución), Rusia, Sudáfrica, Suiza (Confederación Helvética), Turquía, Ucrania, Uganda, Venezuela, Zimbabwe.

\footnotetext{
${ }^{15}$ No pretendemos ser categóricos, pero sin duda en el momento de la publicación de ésta investigación habrá otro más en la lista.
} 
Por continentes tenemos que las Constituciones con datos de bioética están dispersas de la siguiente manera: 1 en Asia, 7 en América del Sur, 7 en Centro América, 2 en Norteamérica, 16 en Europa y 4 en África.

Del análisis del Derecho Constitucional comparado podemos concluir que el tratamiento de la Bioética y del Derecho genético se resumen en los siguientes principios:

1) Límite a la aplicación y utilización indebida de material genético humano (Ecuador) y Garantía a la identidad genética frente al desarrollo, creación y uso de las tecnologías y en la experimentación científica (Portugal, Ucrania).

La defensa del ser humano no sólo debe estructurarse sobre la base de su aspecto corporal externo sino que actualmente las biotécnicas vienen trabajando con la esencia somático-genética del individuo; de allí que se considere que, al igual que el cuerpo, los componentes, sustancias y secuencias de ADN merecen similar protección. Esto nos hace reflexionar que, como consecuencia del desarrollo de la genómica, el derecho a la integridad viene alcanzando su verdadera dimensión: resguardar totalmente a la persona. Las técnicas de manipulación genética alteran tanto la dignidad como la identidad de la persona y la esencia de la humanidad, es decir, no sólo vulneran derechos individuales (de alguien en especial) sino que atentan contra la biodiversidad, selección biológica natural y heterogeneidad de la humanidad (de todos en general). Si bien la investigación científica es reconocida y promovida, incluso en normas constitucionales, ésta debe tener presente siempre el bienestar del hombre y no utilizarlo como un medio para lograr determinados fines.

2) No a los experimentos médicos o científicos sin consentimiento de la persona (Armenia, Bielorrusia, Croacia, Chechenia, Egipto, Eslovenia, Estonia, Guatemala,
Lituania, Paraguay, Rusia, Santa Fe -Argentina-, Polonia, Sudáfrica, Turquía, Venezuela, Zimbabwe).

El derecho al consentimiento informado es fundamental y surge como consecuencia de la realización de actos médicos. Permite al paciente ser instruido acerca de la intervención médica a aplicársele, con la finalidad de obtener su autorización. Es un derecho reconocido en el Derecho médico de la mayoría de los países e, inclusive, al ser una facultad tan inherente a la persona, debería ser parte del Código Civil (Proyecto Unificado de Código Civil y de Comercio argentino). La garantía al consentimiento informado del paciente para la realización de un análisis genético es indispensable, salvo que por razones de urgencia no pueda esperarse para obtenerlo del propio interesado u otras excepciones establecidas por ley. La decisión de la persona es de tal importancia que debe reconocerse, en el mismo sentido, el derecho a conocer o no la información sobre datos genéticos (derecho a saber y derecho a no saber). Nuestra legislación en materia de la salud indica que nadie puede ser objeto de experimentación para la aplicación de medicamentos, tratamientos, exploración o exhibición con fines docentes sin ser debidamente informado sobre la condición experimental de éstos, de los riesgos que corre y sin que medie previamente su consentimiento escrito. Toda experimentación debe sustentarse en los principios de la Declaración de Helsinki, reconociéndose así el derecho a no ser objeto de experimentación médica o científica sin haber prestado el libre consentimiento, pero dentro de los límites establecidos por las leyes.

3) Preservación de la integridad del patrimonio genético del país (Brasil, Ecuador) y regulación de la bioseguridad de los organismos voluntariamente modificados (Ecuador).

Países con recursos genéticos tan variados y representativos deben considerar normas para su protección, partiendo de un reconocimiento 
constitucional de la conservación y aprovechamiento sostenible de la diversidad biológica. Con esta norma general se busca proteger la salud humana, el ambiente y la diversidad biológica; promoviendo la seguridad en la investigación y desarrollo de la biotecnología en sus aplicaciones para la producción y prestación de servicios; regulando, administrando y controlando los riesgos derivados del uso confinado y la liberación de los organismos voluntariamente modificados.

4) Protección especial a la reproducción humana (Nicaragua, Sudáfrica), control de las nuevas prácticas de reproducción (Proyecto de Constitución de Québec) e igualdad de todos los hijos, incluso de los procreados por asistencia científica (Colombia).

La reproducción es un hecho natural, conjunto, libre y decidido por la pareja de manera que no puede ser delimitado ni mucho menos violentado en su esencia. El Estado debe brindar una atención especial en materia de salud reproductiva y ésta es una labor bastante extensa que no se agota sólo en el tema de la paternidad responsable sino que va desde la enseñanza escolar pasando por el cuidado de la madre gestante.

La infertilidad, como una deficiencia que impide a la pareja la procreación, debe ser combatida dentro de los cánones propios de cada país. No son iguales las condiciones de infertilidad en los países industrializados que en los países en vías de desarrollo, ni en los países nórdicos de aquéllos vecinos a la línea ecuatorial. Existe la necesidad que cada estado fije su política para legitimar las técnicas de procreación, pues se parte de la premisa de que toda persona tiene derecho a recurrir al tratamiento de su infertilidad y, si bien las técnicas de reproducción asistida se han convertido en medios efectivos para lograr tener descendencia, las mismas deben ser aplicadas con criterios claros, definidos y reconocidos por la ley. Por ningún motivo pueden ser llevadas a cabo de manera alternativa (antojadiza) sino que únicamente se realizarán con fines supletorios (suplentes), es decir, comprobada la infertilidad, las técnicas de reproducción se presentan como el último medio para lograr la descendencia.

Esto indica una protección integral de la persona frente a la procreática y de aquella nueva forma de discriminación, el genoísmo, que puede reflejarse en diferenciaciones entre los hijos concebidos naturalmente de aquéllos concebidos de manera asistida. De esta manera, se estará limitando la utilización alternativa o antojadiza de las técnicas de procreación y de todas sus derivaciones biotecnológicas (crioconservación, maternidad subrogada, embriones de paternidad múltiple, etc.). En este principio subyace la prohibición de utilizar técnicas de fecundación o de generación de vida con fines distintos a la procreación (clonación y otras).

5) Promoción del derecho a investigar la paternidad (Bolivia, Costa Rica, Cuba, España, El Salvador, Guatemala, Honduras, Italia, Panamá, Uganda, Venezuela) y reconocimiento del derecho a la identidad biológica (Venezuela) o de origen (Buenos Aires, Argentina).

La ley forja el derecho de toda persona de contar jurídicamente con un padre y una madre. A pesar de que la investigación del nexo filial está amparada en normas especiales, como el Código Civil y el Código de los niños y adolescentes (y en algunos países en el Código de familia), su reconocimiento constitucional es imprescindible, pues fortalece el principio de protección de la familia. Sobre este orden de ideas debemos afirmar, además, que filiación, identidad y paternidad no son conceptos exclusivos del Derecho Civil, son también de interés del Derecho Constitucional, pues a través de ellos se establecen vínculos jurídicos de protección al sujeto de derecho y, en especial, a la niñez. 
Los principios en la investigación y determinación de la paternidad subyacen en los siguientes criterios: la filiación, la maternidad y la familia son instituciones sociales y, por demás, naturales, de las que se desprenden la protección de la persona y la familia, la unidad de la filiación y la promoción de la investigación de la paternidad; el derecho a la identidad; el derecho a la investigación de la paternidad; el derecho a conocer el propio origen biológico y la legalidad de la aplicación de pruebas biogenéticas, y sobre este sentido se ha ido resolviendo jurisprudencialmente muchos casos antes de la modificación de nuestro Código Civil, en el que se liberalizó la investigación de la paternidad. En efecto, dada la insuficiencia de las normas privadas, los criterios judiciales se apartaron de las consideraciones taxativas y esquemáticas de la determinación de paternidad extramatrimonial del Código Civil y se ciñeron a las normas constitucionales referidas al respeto y defensa de los derechos fundamentales de las personas y a la protección de la niñez, como principio básico para resolver la pretensión de filiación extramatrimonial(3).

6) Promoción de la medicina tradicional con sujeción a principios bioéticos (Venezuela) y regulación de la práctica médica (Washington).

La medicina tradicional requiere de una normatividad especial y de un reconocimiento constitucional, tomando en cuenta que la ciencia del curar en el Perú se remonta a épocas muy primitivas y que ha ido pasando de generación en generación, sin protección ni normas que cautelen su preservación y diversidad (medicina folclórica, plantas medicinales, hoja de coca y la medicina tropical). Por ello la medicina ancestral, como parte de la idiosincrasia y cultura de la protección de la salud, debe ser impulsada por el Estado reconociendo que la cultura y costumbres son elementos fundamentales en la decisión de la persona para cuidar de su salud.
No debemos olvidar la regulación de la medicina en general, pues como ciencia de la salud tiene al ser humano como parte de su actividad, y allí radica la importancia y el reconocimiento que debe dársele a la praxis médica. Una mención especial merecen los experimentos de ingeniería genética que deben controlarse estrictamente y obligar a los laboratorios, hospitales y universidades que los realizan a informar periódicamente a las autoridades médicas de sus avances, fracasos y resultados de sus trabajos. La terapia genética se ha convertido en un dilema para las autoridades mundiales que no saben si prohibirla debido a los peligros que implica, permitir su desarrollo como último recurso vital o liberalizarla completamente por los éxitos logrados.

7) Respeto a las generaciones futuras (Buenos Aires y Santa Cruz, Argentina; Brasil; Japón; Noruega).

El hábitat ha de ser cuidado también para nuestras generaciones venideras para que gocen de un mundo genéticamente limpio y sean concebidas libres de todo tipo de manipulaciones. Ya no debemos pensar sólo en el individuo sino en la colectividad, no en el homo sino en el hábitat. Es más, este esquema de categorización de la humanidad como un nuevo sujeto de derecho robustece la teoría del concepturus en el sentido que siendo la humanidad un ser jurídico ideal, que contiene a todos los seres humanos, incluso a las generaciones futuras o venideras, merece una cautela jurídica constitucional especial. Este principio reconoce dos documentos trascendentales: la Declaración Universal de los Derechos Humanos de las generaciones futuras ${ }^{16}$ y la Declaración sobre las responsabilidades de las generaciones actuales sobre las generaciones futuras ${ }^{17}$.

\footnotetext{
${ }^{16}$ UNESCO, $145^{a}$ reunión, París, 22/9/1994.

${ }^{17}$ UNESCO, $29^{a}$ reunión, París, 12/11/997.
} 
Pero la precursora en la regulación constitucional de la Bioética es la Confederación Helvética (Suiza) desde 1992. Es más, su actual Constitución de 1999, en tres extensos artículos ${ }^{18}$, protege al hombre y a su hábitat contra los abusos en materia de técnicas de procreación y manipulación genética sobre la base de los siguientes principios: derecho al uso de la medicina reproductiva e ingeniería genética en el ámbito humano y protección frente a sus

\footnotetext{
18 Artículo 118.- Protección de la salud. 1. En el ámbito de su competencia la Confederación brinda tutela a la salud. 2. Prescribe: a. El derecho a los alimentos, medicinas, estupefacientes, organismos, sustancias químicas y objetos o materiales necesarios para la salud. b. Lucha contra la enfermedades transmisibles del hombre y del animal. c La protección de la radiación ionizante. Artículo 119.- Medicina reproductiva e ingeniería genética en el ámbito humano. 1. Todo ser humano es protegido del abuso de la medicina reproductiva y de la ingeniería genética. 2. La Confederación prescribe el derecho al patrimonio germinal y genético humano. En tal ámbito prevé una tutela a la dignidad humana, la persona y la familia y se rige en particular por los siguientes principios: a. Todo tipo de clonación e intervención genética de las células germinales y del embrión humano son inadmisibles. b. El patrimonio germinal y genético no humano no puede ser transferido al patrimonio genético humano, ni a la inversa. c. Las técnicas de procreación asistida pueden ser aplicadas sólo para suplir problemas de infertilidad o para evitar la transmisibilidad de enfermedades de mal grave o hereditarias, no pueden ser utilizadas para predeterminar las características del concebido o para fines de investigación; la fecundación de óvulos humanos fuera del cuerpo de la mujer es permitida sólo por las condiciones establecidas por la ley; fuera del cuerpo de la mujer puede permitirse el desarrollo del embrión sólo si el ovocito humano es transplantado a la mujer inmediatamente. d. La donación de embrión y toda otra forma de maternidad sustituta son inadmisibles. e. No se permite el comercio del patrimonio germinal humano ni de los productos del embrión. f. El patrimonio genético de una persona puede ser analizado, registrado o revelado sólo con el consentimiento y sobre la base de la prescripción legal. g. Cada persona tiene acceso a sus datos genéticos. Artículo 119.Medicina de trasplante. 1. La Confederación regula la materia referida a los transplantes de órganos, tejido y células. En dicho ámbito protege la dignidad humana, la personalidad y la salud. 2. Los criterios particulares para la atribución de órganos deben ser iguales. 3. La donación de órganos, tejidos y células humanas es gratuita. El comercio de órganos humanos está prohibido. Artículo 120.- Ingeniería genética en el ámbito no humano. 1. Todo ser humano y su ambiente deben ser protegidos del abuso de la ingeniería genética. 2. La Confederación prescribe el derecho al patrimonio germinal y genético de los animales, plantas y otros organismos. En tal ámbito tiene en cuenta la dignidad de las criaturas así como de la seguridad del ser humano, de los animales y del ambiente y protege la variedad genética de las especies animales y vegetales.
}

abusos; las técnicas de procreación podrán ser utilizadas para suplir la infertilidad o evitar la transmisibilidad de enfermedades; inadmisibilidad de la donación de embriones y de la maternidad sustituta; el patrimonio germinal humano y los productos del embrión no son comerciables; el patrimonio genético humano puede ser analizado, registrado o revelado sólo con el consentimiento; cada persona tiene acceso a sus datos genéticos; reconocimiento legal del transplante de células; protección del uso de la ingeniería genética en el ámbito no humano. Si bien estas normas resultan en exceso detallistas es de tomar en cuenta la importancia que se da a la Bioética y a la aplicación de la medicina en esta Constitución.

Siguiendo esta línea de juridificación constitucional de la biomedicina, la Carta de los derechos fundamentales de la Unión Europea $(2000)^{19}$-que viene a ser un modelo primigenio de la futura Constitución de la Unión Europea- considera una protección especial al derecho a la integridad de la persona, mencionando que en el marco de la medicina y la biología se respetarán en particular: el consentimiento libre e informado de la persona; la prohibición de las prácticas eugenésicas y, en particular, las que tienen por finalidad la selección de las personas; la prohibición de que el cuerpo humano o partes del mismo se conviertan en objeto de lucro; la prohibición de la clonación reproductora de seres humanos. Asimismo, en el tema de la igualdad, prohíbe toda discriminación y, en particular, la ejercida por razón de características genéticas, entre otras.

\footnotetext{
${ }^{19}$ Diario Oficial de la Comunidades Europeas, 18/12/2000, 2000/C, 364/01. La Comisión Europea emitió la Carta de Derechos Fundamentales de la Unión Europea en la que se recogen los valores comunes que sirvan de referencia a los ciudadanos de la Unión. Este documento es el embrión de una futura Constitución Europea pues se trata de un marco general global de derechos ciudadanos. Es aprobada por el Consejo Europeo en su reunión de Biarritz del 14 de octubre 2000. Oficialmente proclamada durante la reunión del Consejo Europeo de Niza por los Presidentes del Parlamento Europeo, del Consejo y de la Comisión el 7 de diciembre 2000.
} 


\section{Bates y embates bioéticos en el Dere- cho Constitucional peruano}

En el Perú, los derechos a la vida y a la salud fueron plasmados como garantías constitucionales de manera expresa en las Constituciones de 1856, 1860, 1867, 1920 y 1933. Recién con la Constitución de 1979 y en la vigente, de 1993, se tratan de manera orgánica y detallada los derechos fundamentales de la persona. También se desarrollan los derechos sociales, la seguridad social, la salud y el bienestar así como la educación, la ciencia y la cultura. En cada uno de éstos podemos apreciar ocultos algunos principios de orden bioético, como es la protección del derecho a la vida, a la integridad, protección de la madre, el niño, anciano, el discapacitado, la protección del medio ambiente. Sin embargo, el avance, la definición teórica y la plasmación de los postulados bioéticos en documentos internacionales nos hace reflexionar acerca de la imperante necesidad de que un texto constitucional trate tan novedosa y actual materia.

Dentro de esta línea, en Perú hubo una intención de elevar a carácter constitucional la protección de la vida frente al desarrollo biotecnológico. En 1993 la Comisión de Constitución del Congreso Constituyente Democrático aprobó un dispositivo (artículo 7) cuyo tenor mencionaba que "el Estado garantiza la vida del concebido. Lo protege de todo experimento o manipulación genética contrario a su integridad o desarrollo" 20 . Este texto no fue considerado en la Constitución aprobada por referéndum, perdiendo la oportunidad de legislar sobre esta materia.

Por su parte, en los Lineamientos para una Reforma Constitucional presentados por la Comisión de Estudio de las Bases de la Reforma Constitucional del Perú21 de 2001, no se to-

\footnotetext{
${ }^{20}$ Diario Oficial El Peruano, Lima, 7/3/1993; D: 2.

${ }^{21}$ Diario Oficial El Peruano, Suplemento especial editado por el Ministerio de Justicia, Lima, 26/7/2001: 24.
}

maron en cuenta los principios bioéticos que se consideran en el Derecho Constitucional comparado.

Esto nos lleva a pensar que nuestros legisladores y expertos en la materia constitucional nacional, preocupados por otros temas -no menos importantes, pero coyunturales en nuestro medio- no llegaron a reflexionar acerca de la trascendencia de la biotecnología y su repercusión en la vida de los peruanos, ni mucho menos sintieron la importancia de regular constitucionalmente tan elemental materia.

Preocupados por este tema, y aprovechando la oportunidad actual en la que se viene revisando y estudiando las perspectivas de una futura Constitución, preparamos una propuesta la que, con fecha 11 de febrero de 2002, presentamos a la Comisión de Constitución del Congreso de la República bajo la ponencia denominada "La Bioética en las Constituciones del mundo"; en ella consta el articulado sobre principios bioéticos y de Derecho Genético que consideramos deberían ser analizados en el proceso de reforma de la Constitución. Esta propuesta, preparada por iniciativa y solicitud del maestro Carlos Fernández Sessarego (asesor de la Comisión), busca incorporar en la futura Constitución peruana normas que regulen la biotecnología, la procreática y la genómica, en defensa de la vida. Esta misma propuesta, con algunos ajustes, fue presentada a la Comisión de Reforma de la Constitución Política del Perú nombrada por el Ministerio de Justicia. Lastimosamente la propuesta llegó tarde, la Comisión había trabajado a paso de campaña, con rapidez y eficiencia, y había terminado su trabajo. Sin embargo, el viceministro de Justicia Pedro Cateriano Bellido, determinando la importancia del tema, mediante oficio del 7 de marzo de 2002, la remitió al presidente de la Comisión de Constitución del Congreso. 


\section{Los principios bioéticos en la futura Constitución Política del Perú}

Los antecedentes del Derecho Constitucional comparado mencionados y el momento actual en el que se viene estudiando los temas de la futura Carta Magna justifican la incorporación de preceptos de orden y corte bioético. Teniendo en cuenta la estructura de la Constitución Política del Perú de 1993 se propone las siguientes normas a efectos de ser analizadas e incorporadas en la futura Constitución peruana.

\section{DE LA PERSONA Y DE LA SOCIEDAD: DERECHOS FUNDAMENTALES DE LA PERSONA}

Toda persona tiene derecho:

- A la igualdad ante la ley. Nadie debe ser discriminado por motivo de origen, raza, sexo, característica genética, idioma, religión, opinión, condición económica o de cualquiera otra índole.

- A la protección frente a todo experimento médico contrario a su dignidad tomándose en cuenta que la protección del ser humano prevalece sobre el interés de la sociedad y de la ciencia. Nadie puede ser sometido sin su consentimiento a experimentos médicos ni científicos.

- A la protección de su identidad genética. El patrimonio germinal y genético humano será protegido de toda forma de intervención, teniendo en cuenta la defensa de la dignidad de la persona y la familia.

- A la confidencialidad de sus datos genéticos. El patrimonio genético sólo puede ser analizado, registrado o revelado con el consentimiento informado de la persona o en virtud de la ley, reconociéndosele el libre acceso a sus datos genéticos.
- Al acceso a los progresos biotecnológicos en materia de genoma humano respetándose su dignidad humana.

\section{DE LOS DERECHOS SOCIALES Y ECONÓ- MICOS}

- La comunidad y el Estado protegen especialmente al niño, al adolescente, a la madre y al anciano en situación de abandono. También protegen a la familia, promueven el matrimonio y se promociona el derecho a investigar la paternidad. Reconocen a éstos como institutos naturales y fundamentales de la sociedad.

La forma del matrimonio y las causas de separación y de disolución son reguladas por la ley.

- Todos tienen derecho a la protección de su salud, la del medio familiar y la de la comunidad así como el deber de contribuir a su promoción y defensa. Todo experimento médico o científico debe contar con el consentimiento informado de la persona. $\mathrm{La}$ persona incapacitada para velar por sí misma a causa de una deficiencia física o mental tiene derecho al respeto de su dignidad y a un régimen legal de protección, atención, readaptación y seguridad.

- La educación promueve el conocimiento, el aprendizaje y la práctica de las humanidades, la ciencia, la técnica, las artes, la educación física y el deporte. Prepara para la vida y el trabajo y fomenta la solidaridad.

Es deber del Estado promover el desarrollo científico y tecnológico del país fomentando la difusión del principio de respeto de la dignidad y los derechos humanos.

La formación ética y cívica y la enseñanza de la Constitución y de los derechos humanos son obligatorias en todo el proceso educativo civil o militar. La educación religiosa se imparte con respeto a la libertad de las conciencias. 
La enseñanza se imparte, en todos sus niveles, con sujeción a los principios constitucionales y a los fines de la correspondiente institución educativa.

Los medios de comunicación social deben colaborar con el Estado en la educación y en la formación moral y cultural.

\section{DELAMBIENTE Y LOS RECURSOS NATU- RALES}

- El Estado determina la política nacional del ambiente. Se impone el deber de defender $y$ preservar al medio ambiente ecológicamente equilibrado para las generaciones presentes y futuras. Asimismo, promueve el uso sostenible de sus recursos naturales.

- El Estado reconoce la integridad del patrimonio germinal y genético de los animales, plantas y otros organismos protegiéndolo de los usos indebidos de la biotecnología.

- El Estado está obligado a promover la conservación de la diversidad biológica y de las áreas naturales protegidas. Es tarea esencial del Estado la preservación de la integridad del patrimonio germinal y genético del país, la regulación de la bioseguridad de los organismos voluntariamente modificados, la fiscalización de las entidades dedicadas a la investigación y manipulación de material genético, el control de la producción, la comercialización y el empleo de técnicas, métodos y substancias que comporten riesgo para la vida y el medio ambiente.

\section{Planteamiento de los principios propues- tos}

La propuesta está estructurada sobre la base de los siguientes postulados:

- Prohibición a la discriminación genética
- La experimentación médica respetará la dignidad humana

- Reconocimiento del derecho al consentimiento informado

- Primacía del derecho a la identidad genética

- Protección del derecho al patrimonio germinal y genético

- Reconocimiento del derecho a la intimidad genética

- El derecho al acceso a los progresos genómicos

- Promoción del derecho a la investigación de la paternidad

- El desarrollo científico y tecnológico se canalizará tomando en cuenta la dignidad y los derechos humanos

- Defensa y reconocimiento de los derechos de las generaciones futuras

- Preservación del patrimonio genético del país

- Regulación de los organismos voluntariamente modificados

- La difusión de los principios bioéticos en la educación

- Fiscalización de los entes dedicados a la investigación y manipulación genética

- Control de la producción, comercialización y empleo de técnicas y substancias riesgosas que comporten riesgo para la vida y el medio ambiente

Puede decirse que con esta normativa el ser humano está resguardado in extenso. Claro que con el tiempo van a darse situaciones ajenas o fuera de este contexto normativo propio del desarrollo biotecnológico. Sin embargo, consideramos que la propuesta es seria $\mathrm{y}$, por lo demás, actual; por ello nos sumamos al pensamiento de Bellver Capella quien sostiene que "... la ubicación de los problemas bioéticos en sede de interpretación constitucional y no de fundamentación extraconstitucional resulta ventajosa porque centra el debate en el ámbito de lo público: aquél en el que no se rivaliza por la imposición de una concepción global del bien, sino en el que se confrontan visiones del mundo con el objeto de conseguir el respeto a 
la dignidad del ser humano y la convivencia pacífica entre los hombres"(4).

En este sentido, hay opiniones favorables como la del bioeticista español Francisco León ${ }^{22}$, quien se refiere a esta propuesta aludiendo que la defensa del ser humano está garantizada ante la biotecnología, pues en la propuesta da los principios generales, sin descender a cuestiones muy concretas, que merecen un tratamiento distinto, con leyes apropiadas: investigación con células madre, clonación terapéutica. Por su parte, el médico uruguayo Hugo Rodríguez Almada ${ }^{23}$ nos refirió que el contenido plasma muy bien las respuestas adecuadas a los desafíos de la humanidad a esta hora y que me parece un documento de avanzada que, si no me equivoco, convertiría a Perú en el primer país de América Latina con una carta novedosa. El colombiano Juan Camilo Salas Cardona ${ }^{24}$ nos dice que "me parece muy sensato, completo y bien elaborado hablando en términos de técnica jurídica constitucional”.

Sin duda el entendimiento y cada vez mejor comprensión de la Bioética radicará en la difusión de sus principios y la enseñanza en el sistema educacional. Ya sobre el tema existen posiciones claras, como las de Juan Camilo Salas Cardona, que se refieren a la Bioética educativa en sus categorías: 1) la educación en perspectiva de un desarrollo humano integral (haciendo referencia al desarrollo de las dimensiones de la persona) y, 2) la precisión de ésta como un «derecho y un deber» que el Estado debe garantizar en sus primeras etapas. Tóme-

\footnotetext{
${ }^{22}$ Doctor en Filosofía y Magíster en Bioética, Director del grupo de Bioética de Galicia y de la revista Cuadernos de Bioética. Secretario de la Asociación Española de Bioética.

${ }^{23}$ Médico. Miembro de la Sociedad Iberoamericana de Derecho Médico (SIDEME). Especialista en Historia Clínica. Conferencista y consultor en aspectos legales de Historia Clínica.

${ }^{24}$ Abogado, filósofo, teólogo y bioeticista.
}

se en cuenta que los textos jurídicos contemporáneos hablan de que la educación debe ser no sólo un derecho sino una «obligación» para los menores, para evitar el descuido de los padres y el sometimiento al trabajo de los menores y, en últimas, porque eso garantiza el desarrollo social, lo que es parte esencial de la Bioética.

\section{Propuestas de la Comisión de estudio de las bases de la Reforma Constitucional del Perú del Congreso de la República del Perú}

La Comisión de Constitución, Reglamento y Acusaciones Constitucionales del Congreso de la República del Perú preparó el Anteproyecto de Ley de Reforma de la Constitución (texto para el debate $)^{25}$, considerando dos temas importantes sobre Bioética en su Título I: Derechos Fundamentales, Deberes y Procesos Constitucionales, Capítulo I: De los derechos fundamentales. Éstos son el derecho a investigar la filiación y la prohibición expresa a la discriminación genética, y lo hace de la siguiente manera:

\section{1) El derecho a investigar la filiación}

Artículo 1.- Derechos de la persona. Toda persona tiene derecho: Inciso 1. Derecho a la vida. A la vida, a su identidad, a su integridad moral, psíquica y física y a su libre desarrollo. El concebido es sujeto de derecho en todo cuanto le favorece. El Estado garantiza el derecho a investigar la propia maternidad y paternidad.

2) La prohibición expresa a la discriminación genética

\footnotetext{
${ }^{25}$ Anteproyecto de Ley de Reforma de la Constitución (Texto para el debate), 5 de abril de 2002. [Sitio en Internet] Disponible en www.congreso.gob.pe Acceso en octubre de 2002.
} 
Artículo 1.- Derechos de la persona. Toda persona tiene derecho: Inciso 2. Derecho a la igualdad. A la igualdad. Está prohibida toda forma de discriminación por motivo de origen, filiación, raza, género, características genéticas, idioma, religión, opinión, condición económica, discapacidad o de cualquier otra índole, que tenga por objeto o por resultado anular o menoscabar el reconocimiento, goce o ejercicio de los derechos de la persona. El Estado promoverá las condiciones para que la igualdad sea real y efectiva, además adoptará medidas positivas a favor de grupos discriminados o marginados.

Carlos Fernández Sessarego preparó un documento, a manera de Breves y Preliminares Comentarios al Anteproyecto de Ley de Reforma de la Constitución, referido a los derechos fundamentales considerados hasta el punto 24 del artículo $1^{\circ}$ del Anteproyecto, en el que indicaba lo siguiente:

\section{Articulo $1^{\circ}$}

\section{Punto 1. El genoma y el embrión}

\section{FUNDAMENTACIÓN}

a) Se ha omitido la protección del genoma humano y del embrión frente a todo experimento genético. Nadie puede ser sometido contra su voluntad a este tipo de experimentos. No se hace referencia a la clonación del ser humano en cuanto tal, que es diferente a la de sus órganos.

b) Si se protege la vida del concebido es importante extender esta tutela a los embriones, que también participan de la vida. Se hace indispensable la protección del genoma en la medida que significa nuestra propia identidad, la misma que debe ser preservada.

c) La clonación del ser humano, en cuanto tal es un imposible. No es concebible duplicar lo que es idéntico a sí mismo. Aparte del aten- tado a la dignidad, habría que preguntarse si pueden existir dos seres humanos con la misma clave genética y, exactamente, con la misma biografía. La clonación supone la existencia de un ser humano que, por ser libre, debería decidir siempre de la misma manera que lo hace el original. ¿Es esto posible? La libertad o centro espiritual, que es el ser mismo de la persona, no se puede duplicar. Ello podrá ocurrir, tal vez, con alguna de las partes de naturaleza que somos en cuanto animales mamíferos.

CONCLUSIÓN: Proponemos la inclusión de un párrafo que, en términos generales, exprese lo siguiente:

"Los embriones, sus células, tejidos no podrán ser cedidos, manipulados o destruidos, salvo casos excepcionales señalados por ley. Está permitida la disposición gratuita para trasplantes de órganos y tejidos de fetos muertos.

Todo experimento médico o científico debe contar con el asentimiento informado de la persona.

\section{Está prohibida la clonación del ser huma- no en cuanto tal".}

\section{Punto 2. La discriminación}

\section{FUNDAMENTACIÓN}

a) La discriminación, en nuestros días, se origina también sobre la base de las características genéticas. El conocimiento del genoma permite saber el tipo de enfermedades o de riesgos de la persona, lo que puede ser tomado en consideración para discriminar a la persona en diversas actividades, sobre todo en el acceso al trabajo o empleo.

b) Por lo expuesto se hace necesario prohibir dicha modalidad de discriminación sobre la base de las características genéticas de la persona. 
CONCLUSIÓN: Proponemos agregar en la prohibición de toda forma de discriminación aquélla que tiene por motivo "las características genéticas”.

\section{A manera de conclusión}

Una protección máxima del ser humano deberá ofrecer la nueva Constitución Política del Perú, consagrando los principios de orden bioético. En efecto, la protección de la vida, salud, identidad e integridad del ser humano, de la humanidad, del ambiente y, en general, de todo organismo natural viviente frente a los avances biotecnológicos requiere una regulación real y efectiva en la que la Constitución, como la norma madre, siente los principios rectores, las directrices vinculantes y sean las normas especiales las que regulen cada caso en particular. "Por la normatividad jurídica y por la legitimidad metajurídica de la Constitución, la bioética está vinculada al marco constitucional, y la solución a los pro- blemas que se le planteen habrá de partir de los principios ahí contenidos"(4). Esta tarea reglamentarista le corresponderá al Derecho genético y al Derecho médico que están en el compromiso de dictar normas adecuadas que propongan, en un primer momento, una reforma al Código Civil, al Código de los niños y adolescentes, a la Ley general de salud y al Código Penal; luego de ello pensar, quizá, en un Código de genética, pero debemos partir de los principios madres reconocidos en la Constitución.

Sobre la base de este análisis comparativo es urgente fijar los parámetros sobre materia bioética en el Perú, aprovechando la oportunidad para que nuestra nueva Carta Magna proteja integralmente al ser humano, con el fin de que no sea material de exploración ni explotación procreacional ni genética. Ello se logrará mediante la legalización de los principios elementales de la bioética en nuestra futura Constitución.

\section{Referencias}

1. Veloso De França G. Direito médico. São Paulo: Fundo editorial BYK: 2001.

2. Figueroa Yáñez G. Derecho Civil de la Persona - Del genoma al nacimiento. Santiago de Chile: Editorial Jurídica de Chile; 2001: 21

3. Varsi Rospigliosi E. Filiación, Derecho y genética. Aproximaciones a la teoría de la filiación biológica. Lima: Fondo de Desarrollo Editorial de la Universidad de Lima - Fondo de cultura económica; 1999: capítulo VI.

4. Bellver Capella V. Bioética y Constitución. Cuadernos de Bioética. Grupo de Investigación en Bioética de Galicia 1998 Vol. IX; 35: 521. 